\title{
An Investigation of EAP Teachers' Views and Experiences of E-Learning Technology
}

\author{
Sundeep Dhillon (1) and Neil Murray *(D)
}

check for

updates

Citation: Dhillon, S.; Murray, N. An Investigation of EAP Teachers' Views and Experiences of E-Learning Technology. Educ. Sci. 2021, 11, 54. https://doi.org/10.3390/

educsci11020054

Academic Editor: Eila Jeronen

Received: 29 December 2020

Accepted: 27 January 2021

Published: 1 February 2021

Publisher's Note: MDPI stays neutral with regard to jurisdictional claims in published maps and institutional affiliations.

Copyright: (c) 2021 by the authors. Licensee MDPI, Basel, Switzerland. This article is an open access article distributed under the terms and conditions of the Creative Commons Attribution (CC BY) license (https:/ / creativecommons.org/licenses/by/ $4.0 /)$.
Department of Applied Linguistics, University of Warwick, Coventry CV4 7AL, UK; S.Dhillon.5@warwick.ac.uk * Correspondence: N.L.Murray@warwick.ac.uk

\begin{abstract}
The near universal use of electronic learning (e-learning) in higher education (HE) today requires that students and teachers are equipped with the requisite digital literacy skills. The smallscale pilot study we report on here explored the views and experiences of EAP (English for Academic Purposes) teachers regarding their development of digital literacy skills, their application of e-learning technology in their teaching, and their perceptions of its value as a learning tool—areas on which there has been little research to date. A convergent parallel mixed methods approach was adopted, in which a survey was administered to the research participants and a follow-up focus group conducted. The data were analysed, with findings revealing that the EAP practitioners surveyed utilised a range of online tools such as video, plagiarism software and corpus linguistics tools. A number of benefits and limitations associated with e-learning were cited by participants, including increased student engagement and motivation, the development of learner autonomy, and the cultural capital it represented in respect of students' future careers. Meanwhile, the limitations identified included a lack of time for teachers to develop digital literacy and insufficient pre- and in-service training opportunities focused on the effective use of digital technologies and managing technical issues. We conclude with a series of recommendations to facilitate EAP teachers' development and use of e-learning in their practice.
\end{abstract}

Keywords: e-learning; English for Academic Purposes (EAP); digital literacy; teacher education; language teacher professional development

\section{Introduction}

E-learning today increasingly features as a staple of educational life, despite there being inevitable degrees of variation according to local context and the availability of resources. It has been defined by Clark and Mayer [1] as "instruction delivered on a digital device (e.g., a desktop/laptop computer, tablet, smart phone) that is intended to support learning" (p. 8). Meanwhile, Jung [2] has referred to it as "electronically supported learning and teaching of any kind" (p. 221). We employ the term here to refer to the use of computers and digital devices in teaching and learning, including online learning, computer-assisted language learning (CALL), technology-enhanced language learning (TELL) and mobile-assisted language learning (MALL).

The increased prevalence of e-learning technology in education means that there is a widespread assumption that most students will be competent in its use such that they are able to conduct internet research, engage in online forums, communicate via email, and complete and submit assignments electronically using institutional platforms. This is as true for students of English for Academic Purposes (EAP) as it is for other subjects of study. In addition to using electronic systems for record-keeping, uploading materials to virtual learning environments (VLEs), communicating with students and accessing the intranet, teachers are similarly expected to demonstrate familiarity with and competency in using a variety of electronic teaching and learning tools in their classrooms and lecture theatres. If they are to do so effectively, EAP teachers and students require appropriate levels of 
digital literacy [3-5], defined by Dudeney, Hockly and Pegrum [6] as "the individual and social skills needed to effectively interpret, manage, share and create meaning in the growing range of digital communication channels" (p. 2). This, they say, requires not only technical competence but also the ability to use technology "effectively to locate resources, communicate ideas, and build collaborations across personal, social, economic, political and cultural boundaries." (p. 2). Those who lack such skills have been termed "digital immigrants" [7], reflecting the fact that they have not grown up with computers and may, therefore, lack the kind of fluency with digital devices that is more commonplace among their younger counterparts-widely regarded as "digital natives" [7]. As such, they are likely to be disadvantaged in today's educational environment. However, the assumption underlying this distinction, that age is a major factor in technology use and "all modern young people are intrinsically interested in, motivated by, and expert with digital technologies", has been called into question by Pegrum [8], who claims that while many young people are tech-comfy, few are tech-savvy, and some are neither (p. 52). Walker and White [9] similarly argue that " ... whilst there are definitely people who are more or less confident with new technology, the difference is not simply due to age, but to a combination of interest and need" (p. 23), and there is certainly an argument for EAP teachers assuming the role of technological mentors with responsibility for developing students' digital literacy skills in order to support their academic development $[4,10,11]$ an issue to which we shall return later.

Marcelo and Yot-Dominguez [12] found user confidence and the provision of appropriate training to be key determinants in the uptake of technologies by teachers. Kessler and Plakans [13] discovered that "contextually confident" language teachers displayed wellintegrated use of learning technology; however, time for practice was seen as important by all teachers in their study as it afforded them the opportunity to gain familiarity with technology. Similarly, in Liu and Kleinsasser's [14] year-long study of a computer-assisted language learning (CALL) professional development programme designed for in-service teachers, several participants initially reported lacking confidence in their own digital literacy skills. While all participants reported the positive impact of the programme, they complained of insufficient time to practice and apply what they had learnt in the classroom. Meanwhile, in her study of EAP teachers, Gilbert [15] found that courses of short duration, allied to the need to cover the curriculum, mean that it can prove difficult for instructors to find the time needed to "judiciously investigate and integrate" technology into their teaching (p. 140).

\subsection{E-Learning in EAP}

To date, research specifically on e-learning within the EAP context has primarily focused on the development of academic writing skills, particularly via the use of computerised corpora [16]. Gilbert [15], for example, discusses a range of publications regarding concordancing and corpus analysis in EAP, approaches which allow practitioners to "closely examine English as it is actually written and spoken in a range of contexts" (p. 122). While she cites numerous benefits associated with corpora, including the development of teaching and learning materials, increased vocabulary acquisition and the production of context-based vocabulary lists, she notes that the application of concordancing to classroom contexts has been modest (p. 126). Timmis [17], who sees the benefits of corpus analysis to EAP as extending to genres, endorses this view, noting that corpus linguistics is more evident in materials and syllabuses than it is in classroom practice, a situation Tribble and Jones sought to address in their 1990 resource book [18], where they provide instruction on how to create and use concordancing in the language classroom.

Ramachandran [10] argues that the learning potential inherent in new technologies lies in the way they are used as tools for learning rather than in the technologies themselves (p. 80) - a view shared by Walker and White [9], who caution that although EAP students may know how to use computers and the internet, using digital tools effectively for study purposes is something that requires instruction and practice. Charles and Pecorari [19] 
suggest that language learning that utilises multimedia materials and mobile devices helps develop reflective and autonomous learners. Furthermore, they see the use of Web 2.0 tools such as those cited by Gilbert [15] and Chau and Lee [16] —and including social media sites, wikis and blogs-as illustrating the positive impact that technology has on EAP learners' ability to collaborate, upload their work and share it more widely, as well as "to respond to others' content more immediately" [19] (p. 85). Windsor and Park [3] similarly report on the use of structured wiki tasks in an EAP foundation course. While these encouraged student collaboration in preparing essays and also helped develop the reading skills needed to conduct research in preparation for writing tasks, the authors emphasise that students required explicit instruction and support in the technical use of the wiki tools as some students were unfamiliar with them.

Barrett and Liu [20] explored the use of learning technology in EAP oral presentations and conducted a review of related research carried out between 2000 and 2014. They discovered that the online tools most widely researched were those associated with the Web 2.0 phase of internet development (e.g., audio and video blogs, YouTube), while there was a relative paucity of studies focused on social networking sites or personal learning environments for developing oral monologues. They acknowledged that although online tools underwent further development during the period of the review, there is limited research on their effectiveness in relation to the production of EAP oral presentations. They argue that teachers have a "responsibility to learn how to use and teach students to use the tools and courseware for oral monologues" (p. 1263) and call for further training on how to effectively integrate learning technology into EAP teaching.

\subsection{Research Questions}

Our review of the research literature on the use of technology in EAP suggests that the vast majority of studies have tended to focus on individual practitioners' application of a particular online tool or approach in their teaching, and the elicitation of students perspectives on it. In addition, evident is a recent shift in teacher education towards the development of practitioners' facility with e-learning technology through reflection, guided instruction and professional development networks [6,17]. Furthermore, there is an increased focus specifically on the role of the EAP practitioner, their identity and their professional remit $[19,21-23]$. There is, however, relatively little research exploring EAP teachers' perspectives on e-learning technology and the ways in which they acquire proficiency with it and integrate it into their teaching practice. Our small-scale pilot study sought to address this deficit by exploring the following research questions:

(1) How do EAP teachers use e-learning technology?

(2) What are EAP teachers' perceptions of its value as a learning tool?

(3) How do EAP teachers develop their competence in using e-learning technology?

(4) How might teachers' competence in using e-learning technology for EAP teaching be most effectively developed?

\section{Methodology}

Situated within the constructivist paradigm in the hope of gaining insights into the multiple real lives and lived perspectives of EAP teachers in relation to e-learning, the research employed a convergent parallel mixed methods design [24] comprising an online questionnaire and qualitative interviews, and designed to elicit in-depth data pertinent to the research questions. This mixed-method approach was considered appropriate to gain a broad overview of the issues pertinent to the research questions through the online questionnaire, and also elicit more in-depth information from the interviews with the purpose of triangulating the results to enhance the veracity of our interpretation of the data.

The online survey contained a mix of dichotomous, multiple choice, Likert scale and open-ended questions. The dichotomous questions sought to identify whether participants had used a given online tool in their EAP teaching. A "Yes" response led to a multiple- 
choice question on how they had learnt to use it, while a "No" response took respondents to a further question. Participants were asked to respond to 12 statements on the use of e-learning technology via a 7-point Likert scale, where 1 represented "Strongly Agree" and 7 "Strongly Disagree" (Appendix A). Open-ended questions provided an opportunity to provide further details on the benefits, challenges and limitations of using e-learning technology, along with any advice they would give to new or inexperienced EAP teachers concerning its use. Participants were also asked to respond to a series of demographic questions designed to ascertain their age, gender, number of years' experience of teaching $\mathrm{EAP}$, and qualifications. The online questionnaire was created using the Qualtrics survey platform and piloted with three ESOL (English to Speakers of Other Languages) teachers who had no EAP experience and would not be asked to complete the live survey. Using a snowballing and convenience sampling strategy, the final survey was sent to the researchers' personal EAP contacts via an email embedded in which there was a link to the survey that could be forwarded to other teachers. Notification of the research with a link to the survey was also distributed via the BALEAP (British Association of Lecturers in English for Academic Purposes) mail-list. BALEAP is the foremost UK professional body committed to the development of EAP teachers and their practice. A total of 55 respondents completed the survey, 29 female and 26 male. All were between the ages of 18 and 65 . Of the 55 survey respondents, $65 \%$ had up to 10 years' EAP teaching experience and $35 \% 11$ years or more. They were also well qualified, with 36 identifying as MA TESOL (Teaching English to Speakers of Other Languages)/Applied Linguistics/ELT qualified, 32 as CELTA qualified (Certificate in English Language Teaching to Adults-run by Cambridge English Language Assessment), and 21 as DELTA qualified (Diploma in English Language Teaching to Adults-run by Cambridge English Language Assessment). A total of 4 participants were interviewed (see Table 1).

Table 1. Interviewee demographic information.

\begin{tabular}{ccccc}
\hline Pseudonym & Participant 1: DU & Participant 2: KM & Participant 3: FH & Participant 4: TL \\
\hline Gender & Female & Female & Male & Female \\
\hline Age & 54 & 42 & 45 & 32 \\
\hline $\begin{array}{c}\text { Number of years } \\
\text { teaching EAP }\end{array}$ & 10 & 8 & 9 & 4 \\
\hline
\end{tabular}

Following the distribution of the online questionnaire, an interview protocol was developed (Appendix B) with a view to probing participants' views, experiences and proposals using a semi-structured interview format. All interviews were audio-recorded and transcribed. Subjects gave their informed consent for inclusion prior to their participation in the study on the explicit understanding that all contributions would be anonymised. No compensation of any kind was proffered as an inducement to participate. The study was conducted in accordance with the Declaration of Helsinki, and the protocol was approved by the Ethics Committee of the university where the research was conducted.

The quantitative data from the online survey were analysed and presented statistically, while the open-ended questions were manually coded, and salient themes identified. The qualitative interview transcriptions were also coded on the same basis, with particular attention being given to any obvious convergence and divergence of participants' statements. The data from both the survey and the interviews were triangulated through undertaking multiple readings of both data sources with a view to identifying points of convergence in respect of common emergent themes [25].

\section{Results and Discussion}

\subsection{EAP Teachers Use of E-Learning Technology}

The interview participants were specifically asked about how they use e-learning technology in their EAP teaching. Of the four interviewees, one indicated that she actively employed e-learning technology, "I enjoy using technology" (TL), and another (DU) that 
she used "a limited range of ones that I'm familiar with". However, of the remaining two interviewees KM stated: "Actually in the classroom itself I don't, apart from using the speakers and the projector, I don't very often use technology", while FH commented: "I generally do not use a lot of e-learning during my teaching. I use Powerpoint, but I do not think this applies. I do however suggest that my students take part on our VLE at the university". As the interviews progressed, all participants gave examples of how they used a variety of online tools.

The results from the initial 15 dichotomous questions that feature in the online survey on participants' use of different online tools (Figure 1) revealed that video was the most commonly used tool in EAP teaching (53/55 positive responses, or $96 \%$ ). Only 6 out of the 15 online tools scored above $50 \%$ positive responses, with none scoring $100 \%$ an indication, perhaps, that the use of technology is far from "normalised" within EAP teaching [26] (p. 23). The prevalence of online video use among teachers also featured in the qualitative data, with participant TL stating: "YouTube videos, so if I wanted to do like a warmer or starter activity or try and engage students ... try and like activate schemata". This idea of online video as a promoter of engagement speaks to Walker and White's idea of breaking free of "the temporal linearity of traditional classroom instruction" [9] (p. 85).

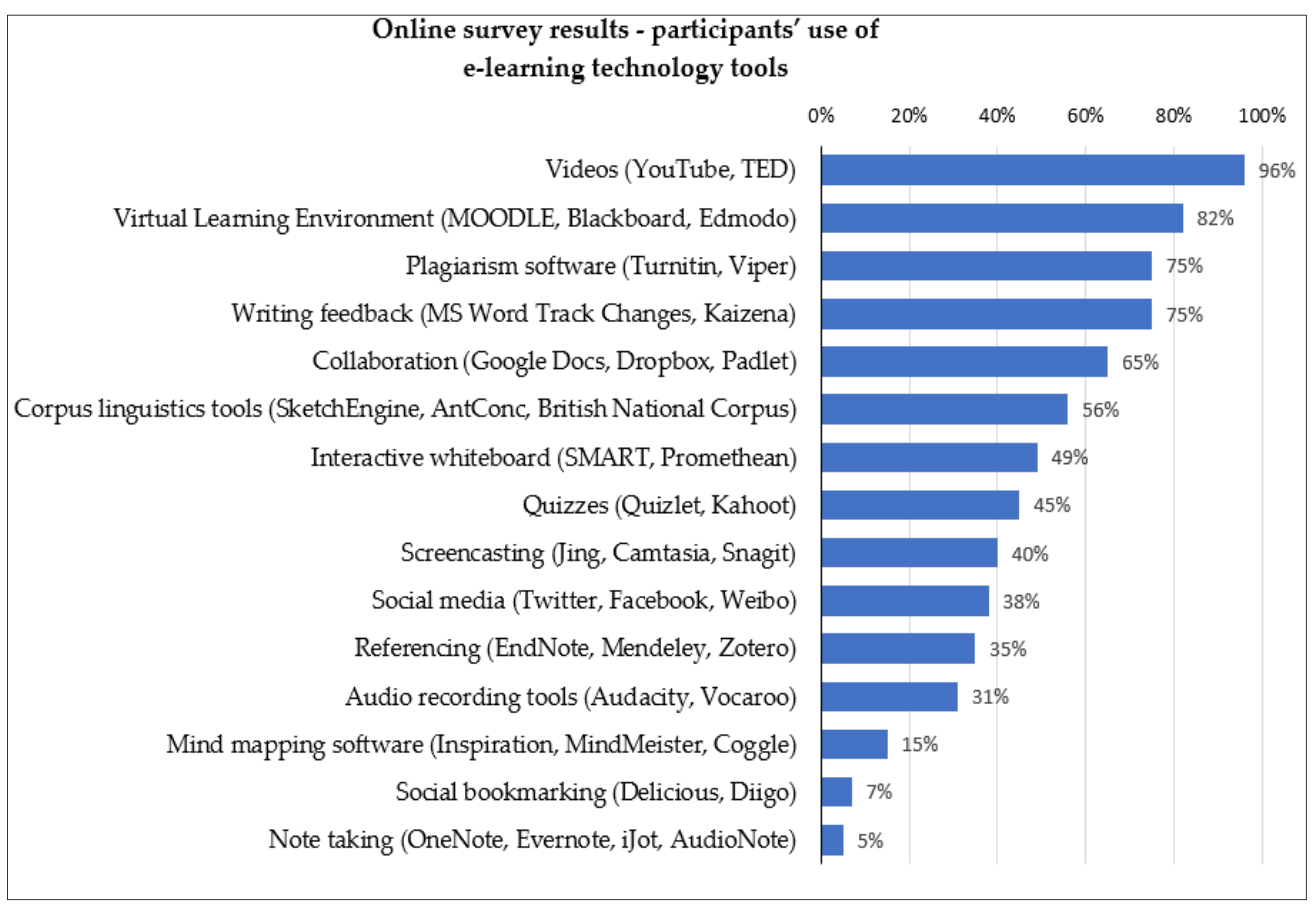

Figure 1. Results from online survey of participants' use of e-learning technology tools.

Virtual learning environments (VLEs) were the second most used tool in EAP teaching, eliciting 45 positive responses ( $85 \%$ ) and featuring in all the interviews. TL displayed a very positive view of Moodle - the VLE used in her workplace-as "a place where learners have the opportunity to learn outside the classroom. I think it's a good tool for teachers to put extra resources for learners". This view reflects the generally positive attitudes to VLEs reported in the literature $[27,28]$. DU's view of Moodle was interesting in that she initially states, "Okay, we use Moodle ... so that students can review lessons and access ... resources, so we use Moodle sort of on a daily basis", but then goes on to add a caveat that, "I tend to just use it for lessons so previous lessons are put there". Although the use of Moodle as outlined by DU would appear to substantiate Carroll's [29] view that it is used primarily as a repository for lesson materials and lacks pedagogical value, DU went on to state that "I know some tutors use the ... forum, they use it in order to communicate with students". She also displays an openness towards extending her use of Moodle that is shared by TL, who commented, "I'd like to expand my knowledge on using VLE, because I believe that this is the future, it's environmentally friendly and interactive. It's also accessible; you can use a computer, laptop, tablet or even a 
smartphone. This all makes it more convenient for students to use". This issue of accessibility is highlighted by Charles and Pecorari [19] (p. 86) as a positive attribute in that "materials are available for use anywhere and at any time", thereby giving students greater control over their learning and helping them to become more reflective and autonomous learners.

In relation to VLEs, KM indicated some familiarity with Blackboard, the platform used in her institution, and gave specific examples of its use within her EAP teaching:

"I use Blackboard to get students maybe to do collaborative kind of peer review things so that they can put up journal entries or pieces of writing and then comment on each other. I have used the wiki facility on Blackboard for students to create kind of a collective vocabulary list."

These activities show how Blackboard was used to promote student collaboration and the development of writing and vocabulary skills. Collaborative tools such as Google Docs, Dropbox and Padlet that provide a "framework for language learning" through "the opportunity for students to create, share and respond to content" [19] (p. 85) scored $65 \%$ positive responses in the survey. KM described Padlet as "really being pushed in the institution for getting students to do collaborative work".

Other online tools which scored highly in the survey were plagiarism software and writing feedback tools. Both scored a $75 \%$ positive response rate that indicated a high level of usage. Corpus linguistics tools scored a $56 \%$ positive response rate, indicating their wider use in EAP teaching than reported by Gilbert [15] and Timmis [17]. It may be that the use of corpora is linked to the qualifications of the survey participants, $65 \%$ of whom indicated they were MA qualified in TESOL, Applied Linguistics or ELT and therefore more likely, perhaps, to have encountered and/or received training in the use of corpus linguistics tools in their courses, particularly where those courses included EAP optional modules where corpora such as BAWE (British Academic Written English) and BASE (British Academic Spoken English) are more likely to have been referenced. It was notable that plagiarism software, writing feedback tools and corpus linguistics tools did not feature in any of the qualitative data. This may be due to the interview participants focusing on those online tools they used with students whilst teaching rather than in the preparation of materials, the marking of assignments and the provision of written feedback.

Interactive whiteboards (IWBs) elicited a $49 \%$ positive response rate among the survey participants and were also referred to in the interviews, although reference was made by two of the interviewees to the need for training in their use ("If we teach on the main campus a couple of the classrooms have electronic whiteboards, but I've never had training on how to use those so I don't ever use those" [KM]). TL stated that she uses an IWB in EAP teaching because-

it's just how we're used to seeing things nowadays. It's convenient. Sometimes, if I need to write something on the board I'll just type it up, it's neater, it's clearer, it's easier to edit, I can save it ... I use it as a visual ... to project things onto the board ... even parts of the course book. I'll also use it for learners to actually come up to the board ... and complete a text with the missing words.

Meanwhile, FH echoes the idea of technology promoting student engagement as well as interaction:

I think [an IWB] helps to keep the students' attention ... this particular tool is helpful as it cannot only be used for your materials, but you can go further with the students as you dive into the internet and the class can be more interactive.

These examples provide evidence of an appreciation of the pedagogical value of IWBs beyond simply providing the "wow factor" for students [30] (p. 539).

Quizzes scored a $45 \%$ positive response rate in the survey and were discussed in the interviews. DU said, “Triptico, or Wordle I've used, Kahoot for revision ... with Triptico you have the word magnets you can use it for matching activities". TL discussed the use of mobile technology as an interactive tool, stating "There's like programmes or apps such as Kahoot and Socrative where you can do quizzes and they could answer using their mobile 
phone". These excerpts highlight the use of quizzes as quick activities to engage students and consolidate learning.

The following tools elicited between $30 \%$ and $40 \%$ positive responses in the survey, although they did not feature in the qualitative data. Screencasting elicited $40 \%$, social media $38 \%$, referencing software $35 \%$, and audio recording tools $31 \%$ positive responses. The three lowest-scoring online tools in the survey were mind-mapping software (15\%), social bookmarking $(7 \%)$ and note-taking tools $(5 \%)$. It may be that due to the timeintensive demands of EAP courses, greater emphasis is placed on the language components and academic skills required for students to successfully complete the EAP programme, with the result that the study skills elements, which would benefit from mind-mapping, social bookmarking and note-taking tools, are largely overlooked. KM did, however, cite examples of how e-learning technology was promoted for use outside of the classroom and in doing so alluded to its value in promoting learner autonomy: "I use it more for students to do self-study things. I recommend apps to them, dictionary apps, pronunciation apps, places they can go to do listening".

\subsection{EAP Teachers' Perceptions of the Value of E-Learning Technology}

\subsubsection{Student Engagement}

A view that e-learning technology in EAP classes benefited students in terms of engagement and motivation emerged strongly from both data sets. In the interviews, $\mathrm{FH}$, for example, commented: " ... it can also help the students to be more engaged as well as piquing an interest in students who generally would rather have their faces in a phone or tablet screen then up towards a teacher lecturing". DU, meanwhile, stressed the importance of linking the technology to communication skills: "I always try and combine it with, you know, getting students to talk about the answers and why they think it's correct", otherwise "It can be quite passive, some digital technology, and that's not a good thing". Survey participants' openended responses frequently made reference to the use of technology being intrinsically more motivating, adding variety and increasing student engagement. Although student engagement featured strongly as a theme in the open-ended question, the statement "EAP students expect teachers to use e-learning technology in classes" scored highest in the "Some agreement" (24\%) and "Neutral" $(24 \%)$ categories. Thus, while teachers are aware of the benefits of e-learning technology in terms of engaging learners, students do not necessarily expect them to utilise it-an expectation that may be the result of teachers not translating their views into practice.

\subsubsection{Development of Autonomous Learners}

E-learning technology was widely seen as promoting learner autonomy by giving students learning opportunities within and outside of the classroom [cf. 19]:

... the great advantage of digital technology is that you can use it outside the classroom and students can access it ... it's useful ... if you can develop student autonomy so that, they can access materials outside of the classroom. (DU)

Notably, $42 \%$ of survey respondents strongly agreed that, "e-learning technology is an effective tool for setting activities for completion outside of the EAP classroom". Open-ended comments included: "it gives them freedom to continue their learning at home" and it promotes "curiosity to develop their EAP independently". The development of learner autonomy may be linked to the common practice among the teachers surveyed $(82 \%)$ of using VLEs in EAP teaching, and thereby providing opportunities for students to access independent learning materials and interactive activities.

\subsubsection{A Dislike of E-Learning Technology for Its Own Sake}

A further theme that appeared in both the survey and interview data concerned the perceived pedagogical value of using e-learning technology in teaching. While its importance has been emphasised by Ramachandran [10] and Chau and Lee [16], KM, for example, stated that: 
there has to be value in it; I think sometimes you can throw something in just because you think, 'oh, the students will like this because it's technology', without thinking about how does it actually support your teaching.

A similar view was expressed by one survey participant as follows:

Make sure you are clear about the pedagogic rationale for tasks which make use of the technology-don't just do it because it seems cool.

Both of these extracts resonate with Bax's view that "CALL will be normalised when computers are treated as always secondary to learning itself, when the needs of learners will be carefully analysed first of all, and then the computer used to serve those needs" [26] (p. 24).

\subsubsection{Relevance to Future Context}

The use of e-learning technology as a means of developing digital skills for use in their academic and future career contexts also emerged as a key theme in the interviews:

I think I should be using it more because I think academic lecturers are using it more, particularly for big class teaching. Therefore, part of our role is to prepare students for that, so I think what we do should be kind of mirroring what happens on academic courses. (KM)

In the survey data, $62 \%$ of respondents either agreed or strongly agreed that e-learning technology should be used to support EAP students in the next stage of their studies. Comments included, "I think technology which mirrors usage in their academic courses and careers is important", and "We have become more digitized and therefore students gain valuable knowledge on how to use new technology for their studies". While this highlights the need for EAP teachers to be competent in using e-learning technology and to undergo any necessary training, this can present challenges, some of which we outline below.

\subsection{Challenges}

The need for student and teacher training on the effective use of e-learning technology was highlighted in the data. Despite comments emphasising the fact that "Certain teachers struggle to use specific technological features ... " and that "... it would be beneficial for teachers to receive regular training", one survey respondent lamented "the lack of training and development" available "to help teachers engage and experiment with new technologies". The fact that time constraints can often limit opportunities for teachers to undergo training in the use of e-learning technology $[15,31]$ featured as a prominent theme in the survey data, where reference was made to "The (often) demanding process of learning the new technology for a relatively limited return" and the fact that "Having to learn how to use it and helping others use it can get time consuming". The challenges around constantly changing technology were also identified as an issue:

I think keeping up to date with what is available to the students and what is available to us as educators is a huge challenge. There are constant updates as well as an ever-increasing interest and influx of new technologies. (FH)

In total, 35\% of survey respondents strongly agreed with the statement that "EAP students should be taught how to use e-learning technology effectively for their future studies". However, it was noted that training students could present problems:

... if you ... have other learners that don't know how to use, for example the VLE, or they're just not good with technology or computers it can ... be a little bit frustrating because firstly you have to teach them how to use the technology before you could actually present work on it or demonstrate things using it. (TL)

Another comment elicited in the survey referred to students "wasting time learning how to use e-learning technology instead of working on their research or production". Technical issues around using technology were also widely cited by participants: 
The basic challenge is that it doesn't work sometimes so ... as a teacher you always have to have a plan B because for any, either it's not working because there's a malfunction $\ldots(D U)$

Other comments focused on the fact of classrooms not being equipped with the necessary hardware as well as insufficient institutional funding of e-learning software, with one survey participant stating that "Software incompatibilities, system failures and a hundred other unexpected failures make it dicey to depend on e-learning tech in EAP classes".

\subsection{EAP Teachers' Approaches to Developing Their Competence in Using E-Learning Technology}

In total, $49 \%$ of our survey respondents strongly agreed with the statement "I am keen to learn more about using e-learning technology in EAP teaching" and were subsequently asked how they had learnt or trained to use the e-learning technology tools they employed in their EAP teaching. A key finding was that, for every tool listed (15/15), the majority of teachers selected the "self-taught" option. While many of the tools referenced, such as video and social media, are commonly used in daily life and as such lend themselves to self-exploration, it was also the case that the teachers' skills in working with more specialist tools, such as corpora and screencasting, were predominantly self-taught. These results call into question the possible correlation, cited earlier, between MA qualifications and the increased use of corpora.

The second most common way of developing conversancy in e-learning technology was via colleagues-a category that was second only to "self-taught" for 9 of the 15 tools listed. These results are consistent with Kessler's [32] research, which found that informal methods of training were used by MA TESOL graduates in order to learn how to use computers in their teaching. The qualitative interviews told a similar story regarding teachers' development of IT skills, with DU, for example, commenting that "We did have some training on Moodle; so that was like one afternoon in the first, in the induction programme. But apart from that we've actually learnt it ourselves". This was echoed by TL in relation to learning about the VLE system used in her institution: "Again, taught myself, there was a short training session here. I think they can show you the basics but you just kind of learn it yourself". FH stated that he preferred to learn from others or by himself:

We can get additional training for using the different platforms available to us, but I have not taken advantage of many of these as I have chosen to learn a lot of this through colleagues as well as trial and error.

The data sets revealed the importance of experimenting with technology in order to help ensure that teachers develop their digital skills and levels of confidence. DU stated, "I suppose the most important skill really is the confidence to know that you can learn how to use that tool". TL highlighted that many tools required similar skills, "I mean if you can use a laptop efficiently, I think extending that skill to use other things like the VLE or IWB ... it shouldn't or wouldn't be that difficult". Meanwhile, the survey data referred to "see[ing] what's out there and play[ing] around with it", and the need to "keep experimenting and trying new things". More practical advice included "Experimenting in advance of classes to familiarise oneself and plan for unforeseen issues that may arise, and knowing how to take advantage of the technology available within one's institution".

In total, $36 \%$ of survey respondents agreed and $25 \%$ strongly agreed with the statement: "There is not enough e-learning technology training in in-service teacher training". This echoes a call in the literature for better training for language teachers in the use of technology [10,30,33]. Kessler's [32] survey of 108 graduates of Masters TESOL programmes, and which focused on the use of online training and social networking as a means of undertaking professional development around the use of e-learning technology, found that they were largely dissatisfied with the instruction received on the use of IT in their teaching. Consistent with Haines' subsequent findings [34] concerning the developmental benefits of teachers' individual experimentation with technology and working with peers, these graduates explored instead-and felt they benefitted from-more informal methods through which to enhance their e-learning capabilities, such as collaborating with others, 
accessing online support and attending conferences. This was reflected in our participants' tendency to rely on experimentation/self-teaching, peer consultation and observation as useful IT training mechanisms, as reported above, along with online and external training: "Join an online community to learn what is available in terms of tools", and "Attend an external course or conference". For teachers striving autonomously to develop themselves in respect of e-learning technologies, social networking sites such as Facebook, Twitter and LinkedIn can certainly help to link global communities of teachers for professional purposes, while video sites (e.g., YouTube, TED, etc.) provide helpful and easily accessible links to learning materials.

In terms of pre-service training, $29 \%$ of survey respondents strongly agreed that they did not receive enough training on using e-learning technology during their pre-service teacher training. DU, a CELTA trainer, explained that on the CELTA course-

We did provide input on tools that we thought students would find useful, which would include software like Triptico. However, as time has gone on, trainees have their own skills that they've brought to the classroom ... sometimes trainees have lots of ideas.

KM stated, "I don't think my DELTA had anything about e-learning ... On my MA TESOL I could have done a module on e-learning but I didn't, it was optional". FH had undertaken an MA in Applied Linguistics and TESOL through distance learning and regularly used video, Blackboard and Moodle, but had not applied this experience of using online tools to his own EAP teaching. KM's comments in respect of the DELTA course would appear not to be consistent with Cambridge English Language Assessment's own claims in relation to the course's practical teaching component and its learning outcomes concerning the use of ICT:

Take into account the potential of ICT in the learning context concerned (e.g., classroom, work place, VLE, etc.)

Evaluate the role of ICT in lesson preparation, delivery and follow up

Adapt, develop and create teaching/learning materials, including ICT, for specified teaching and learning contexts [35] (pp. 4-6)

Of particular note, with respect specifically to EAP, is the extent to which BALEAP addresses the issue of e-learning. BALEAP organises a biennial international conference and numerous events specifically dedicated to EAP (for example, a BALEAP webinar was held in March 2020 with the title "Moving to digital learning and teaching" [36]), and hosts a website with 15 different presentations available covering topics including the use of blogs, Moodle, MALL and audio/visual feedback in EAP. There is also a specific Special Interest Group (SIG) related to technology-enhanced learning, with a separate website and YouTube channel. Notable, however, is the lack of inclusion of digital literacies in the organisation's Competency Framework for Teachers of English for Academic Purposes [37] p. 3), where, as Simpson and Obdalova [38] (pp. 109-110) observe, there is only one relevant statement (under the "Teaching Practices" heading) which stipulates that an EAP teacher should have the ability to "integrate IT into delivery, to enhance IT skills and reflect academic practices" [37] (p. 8). They conclude that, in relation to digital literacies, "this area is either considered beyond the scope of EAP teaching or that inclusion is an innovative approach, yet to be widely adopted" [38] (p. 110).

\section{Conclusions}

This study set out to investigate EAP teachers' attitudes to and use of e-learning technology. The results revealed that video and VLEs are the most readily available and commonly used technological tools, while the use of collaborative tools and corpus linguistic tools also featured widely in both the quantitative and qualitative data. The most frequently cited benefits associated with the use of these tools concerned their ability to promote student engagement and learner autonomy. Our findings indicated, however, that of the fifteen online tools specified in the survey, only six were being used by more than $50 \%$ of the teachers surveyed, with lack of training and lack of confidence in using 
e-learning technology being cited as the principal reasons for a reluctance to engage with the tools available, along with the practical and technical challenges they presented. This lack of training confirms Kessler's [32] and Walker and White's [9] finding that EAP teachers' conversancy in online tools is largely the result of self-learning. Our participants expressed a clear desire for better training opportunities-both pre- and in-service-which they viewed as important to supporting their efforts to understand and more effectively integrate online tools into the curriculum and their classroom practice. This gives weight to the idea that such training needs to form an integral part of universities' continuing professional development strategies, along with a clearly defined proportion of teachers workloads to be earmarked for such development activity. Our participants indicated that institutional training currently tends to consist of one-off or occasional, irregular one-day or half-day courses rather than a more systematic ongoing programme of development. In addition, and alongside systematic training, EAP teachers need to have access to timely IT support to help them deal quickly with any technical issues that arise. This can be complemented by (a) the development of online training modules specifically focused on the use of e-learning technology, and associated resources within the context of EAP, and (b) a concerted effort to develop a local community of practice whereby EAP colleagues share their own learning and practices around the use of such technology. Together, these measures will help build confidence and encourage their competent and effective use both within and outside the classroom. What is certain is that technology will, by its very nature, continue to develop and its use in educational contexts will only increase. It is, therefore, incumbent upon universities to provide teachers and students with access to and training in those technologies, just as it is incumbent on teachers-in this case EAP teachers- to take responsibility for taking up opportunities to develop their expertise and skill in employing them for the benefit of their learners.

Author Contributions: Conceptualisation, S.D. and N.M.; formal analysis, S.D.; investigation, S.D.; methodology, S.D.; supervision, N.M.; writing—original draft, S.D.; writing—review and editing, N.M. All authors have read and agreed to the published version of the manuscript.

Funding: This research received no external funding.

Institutional Review Board Statement: The study was conducted in accordance with the Declaration of Helsinki, and the protocol was approved by the Ethics Committee of the University of Warwick where the research was conducted.

Informed Consent Statement: Informed consent was obtained from all subjects involved in the study.

Data Availability Statement: Not applicable.

Conflicts of Interest: The authors declare no conflict of interest.

\section{Appendix A Survey Likert Statements and Open-Ended Questions}

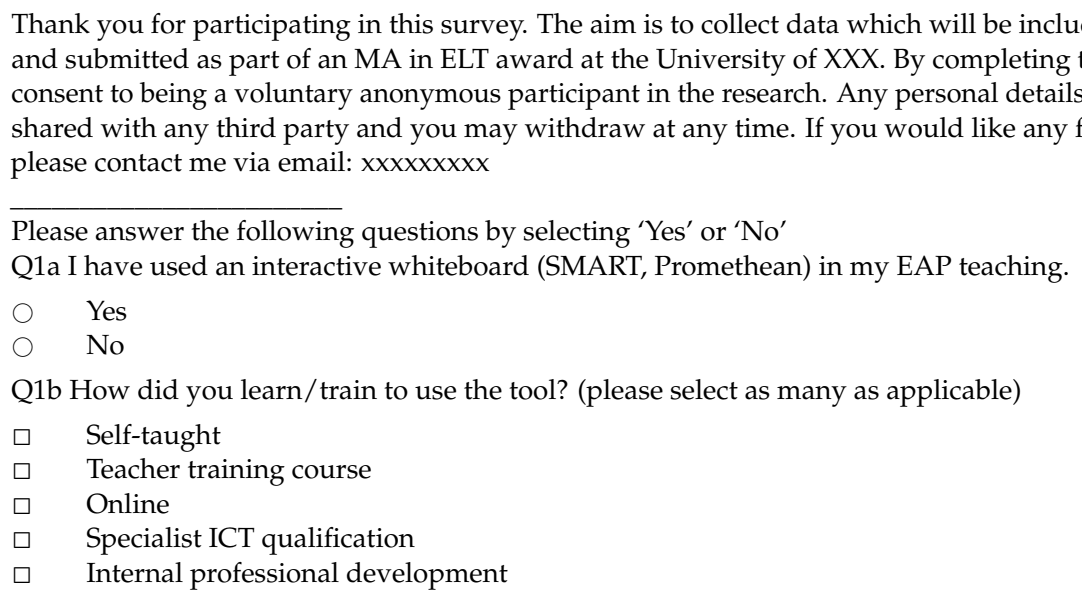




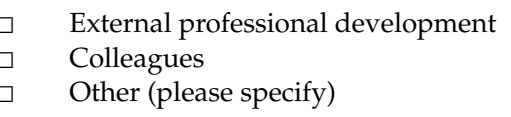

Q2a I have used a Virtual Learning Environment (MOODLE, Blackboard, Edmodo) in my EAP teaching.

Yes

○ No

Q2b How did you learn/train to use the tool? (please select as many as applicable)

$\square \quad$ Self-taught

Teacher training course

Online

Specialist ICT qualification

Internal professional development

External professional development

Colleagues

Other (please specify)

Q3a I have used quizzes (Quizlet, Kahoot) in my EAP teaching.

Yes

No

Q3b How did you learn/train to use the tool? (please select as many as applicable)

Self-taught

Teacher training course

Online

Specialist ICT qualification

Internal professional development

External professional development

Colleagues

Other (please specify)

Q4a I have used referencing software (EndNote, Mendeley, Zotero) in my EAP teaching.

Yes

No

Q4b How did you learn/train to use the tool? (please select as many as applicable)

Self-taught

Teacher training course

Online

Specialist ICT qualification

Internal professional development

External professional development

Colleagues

Other (please specify)

Q5a I have used note taking tools (OneNote, Evernote, iJot, AudioNote) in my EAP teaching.

Yes

No

Q5b How did you learn/train to use the tool? (please select as many as applicable)

Self-taught

Teacher training course

Online

Specialist ICT qualification

Internal professional development

External professional development

Colleagues

Other (please specify)

Q6a I have used screencasting (Jing, Camtasia, Snagit) in my EAP teaching.

Yes

No

Q6b How did you learn/train to use the tool? (please select as many as applicable)

Self-taught

Teacher training course

Online

Specialist ICT qualification

Internal professional development

External professional development

Colleagues

Other (please specify) 
Q7a I have used corpus linguistic tools (SketchEngine, AntConc, British National Corpus) in my EAP teaching.

Yes

No

Q7b How did you learn/train to use the tool? (please select as many as applicable)

Self-taught

Teacher training course

Online

Specialist ICT qualification

Internal professional development

External professional development

Colleagues

Other (please specify)

Q8a I have used videos (YouTube, TED) in my EAP teaching.

Yes

No

Q8b How did you learn/train to use the tool? (please select as many as applicable)

Self-taught

Teacher training course

Online

Specialist ICT qualification

Internal professional development

External professional development

Colleagues

Other (please specify)

Q9a I have used plagiarism software (Turnitin, Viper) in my EAP teaching.

Yes

No

Q9b How did you learn/train to use the tool? (please select as many as applicable)

Self-taught

Teacher training course

Online

Specialist ICT qualification

Internal professional development

External professional development

Colleagues

Other (please specify)

Q10a I have used social media (Twitter, Facebook, Weibo) in my EAP teaching.

Yes

No

Q10b How did you learn/train to use the tool? (please select as many as applicable)

Self-taught

Teacher training course

Online

Specialist ICT qualification

Internal professional development

External professional development

Colleagues

Other (please specify)

Q11a I have used mind mapping software (Inspiration, MindMeister, Coggle) in my EAP teaching.

Yes

No

Q11b How did you learn/train to use the tool? (please select as many as applicable)

Self-taught

Teacher training course

Online

Specialist ICT qualification

Internal professional development

External professional development

Colleagues

Other (please specify)

Q12a I have used writing feedback tools (MS Word Track Changes, Kaizena) in my EAP teaching.

Yes

No 
Q12b How did you learn/train to use the tool? (please select as many as applicable)

Self-taught

Teacher training course

Online

Specialist ICT qualification

Internal professional development

External professional development

Colleagues

Other (please specify)

Q13a I have used collaboration tools (Google Docs, Dropbox, Padlet) in my EAP teaching. Yes No

Q13b How did you learn/train to use the tool? (please select as many as applicable)

Self-taught

Teacher training course

Online

Specialist ICT qualification

Internal professional development

External professional development

Colleagues

Other (please specify)

Q14a I have used social bookmarking websites (Delicious, Diigo) in my EAP teaching. Yes No

Q14b How did you learn/train to use the tool? (please select as many as applicable)

Self-taught

Teacher training course

Online

Specialist ICT qualification

Internal professional development

External professional development

Colleagues

Other (please specify)

Q15a I have used audio recording tools (Audacity, Vocaroo) in my EAP teaching.

Yes

No

Q15b How did you learn/train to use the tool? (please select as many as applicable)

Self-taught

Teacher training course

Online

Specialist ICT qualification

Internal professional development

External professional development

Colleagues

Other (please specify)

Q16 Read each statement and select your opinion from 1 to 7 ( $1=$ Strongly Agree; $7=$ Strongly Disagree $)$

a. I am confident in using e-learning technology in my EAP teaching.

b. It is necessary to use e-learning technology in EAP teaching.

c. I use e-learning technology to present information.

d. It is necessary to keep up-to-date with e-learning technology.

e. There is not enough e-learning technology training in in-service teacher training.

f. EAP students expect teachers to use e-learning technology in classes.

g. I use e-learning technology to give assessment feedback.

h. E-learning technology is an effective tool to set activities for completion outside of the EAP classroom.

i. There is not enough e-learning technology training in pre-service teacher training.

j. I use e-learning technology as an assessment tool.

k. EAP students should be taught how to use e-learning technology effectively for their future studies.

1. There is too much emphasis placed on using e-learning technology in EAP classes.

Q17 What benefits can students derive from using e-learning technology in EAP classes?

Q18 What are the main challenges and limitations of using e-learning technology in EAP?

Q19 What advice would you give to a new or inexperienced EAP teacher on using e-learning technology? 


\section{Appendix B Interview Questions (Guide)}

(1) How long have you been teaching EAP?

(2) How did you train/learn to use different e-learning technology tools? (Can you give some specific examples? Have you undertaken any specific training courses or specialist qualifications in using ICT?)

(3) What e-learning technology is available in your workplace/institution?

(4) What IT support and training is available?

(5) How do you use e-learning technology in your EAP teaching?

(6) What is the value of e-learning technology as a learning tool for EAP?

(7) What are the main challenges in using e-learning technology in EAP?

(8) Which digital literacy skills are most important for EAP teachers?

(9) Do teacher training courses such as the CELTA and DELTA provide instruction on using e-learning technology in the EAP classroom? How effective is this?

(10) Is there any particular e-learning tool that you would like to learn more about to use in your EAP teaching? Why this tool? How would you train/ learn to use it?

\section{References}

1. Clark, R.C.; Mayer, R.E. E-Learning and the Science of Instruction: Proven Guidelines for Consumers and Designers of Multimedia Learning, 4th ed.; John Wiley Sons, Inc.: Hoboken, NJ, USA, 2016.

2. Jung, H.J. Fostering an English teaching environment: Factors influencing English as a Foreign Language teachers' adoption of mobile learning. Inform. Educ. 2015, 14, 219. [CrossRef]

3. Hockly, N. Digital literacies. ELT J. 2012, 66, 108-112. [CrossRef]

4. Windsor, A.; Park, S.S. Designing L2 reading to write tasks in online higher education contexts. J. Engl. Acad. Purp. 2014, 14, 95-105. [CrossRef]

5. Røkenes, F.M.; Krumsvik, R.J. Prepared to teach ESL with ICT? A study of digital competence in Norwegian teacher education. Comput. Educ. 2016, 97, 1-20. [CrossRef]

6. Dudeney, G.; Hockly, N.; Pegrum, M. Digital Literacies: Research and Resources in Language Teaching; Pearson: Harlow, UK, 2013.

7. Prensky, M. Digital natives, digital immigrants. Horizon 2001, 9, 1-6.

8. Pegrum, M. From Blogs to Bombs: The Future of Digital Technologies in Education; UWA Publishing: Crawley, Australia, 2009.

9. Walker, A.; White, G. Technology Enhanced Language Learning: Connecting Theory and Practice; Oxford University Press: Oxford, UK, 2013.

10. Ramachandran, S. Integrating new technologies into language teaching: Two activities for an EAP classroom. TESL Can. J. 2004, 22, 79-90. [CrossRef]

11. Arno-Macia, E.; Rueda-Ramos, C. Promoting reflection on science, technology, and society among engineering students through an EAP online learning environment. J. Engl. Acad. Purp. 2011, 10, 19-31. [CrossRef]

12. Marcelo, C.; Yot-Domínguez, C. From chalk to keyboard in higher education classrooms: Changes and coherence when integrating technological knowledge into pedagogical content knowledge. J. Furth. High. Educ. 2019, 43, 975-988. [CrossRef]

13. Kessler, G.; Plakans, L. Does teachers' confidence with CALL equal innovative and integrated use? Comput. Assist. Lang. Learn. 2008, 21, 269-282. [CrossRef]

14. Liu, M.-H.; Kleinsasser, R.C. Exploring EFL teachers' CALL knowledge and competencies: In-service program perspectives. Lang. Learn. Technol. 2015, 19, 119-138.

15. Gilbert, J. English for academic purposes. In Innovations in Learning Technologies for English Language Teaching; Motteram, G., Ed.; British Council: London, UK, 2013; pp. 117-143.

16. Chau, J.; Lee, A. Technology-enhanced language learning (TeLL): An update and a principled framework for English for Academic Purposes (EAP) courses. Can. J. Learn. Technol. 2014, 40, 1-24. [CrossRef]

17. Timmis, I. Corpus Linguistics for ELT Research and Practice; Routledge: London, UK, 2015.

18. Tribble, C.; Jones, G. Concordances in the Classroom: A Resource Book for Teachers; Longman Group UK Limited: Harlow, UK, 1990.

19. Charles, M.; Pecorari, D. Introducing English for Academic Purposes; Routledge: Abingdon, UK, 2016.

20. Barrett, N.E.; Liu, G.Z. Global trends and research aims for English academic oral presentations: Changes, challenges, and opportunities for learning technology. Rev. Educ. Res. 2016, 86, 1227-1271. [CrossRef]

21. Martin, P. Teachers in transition: The road to EAP. In Cases on Teacher Identity, Diversity, and Cognition in Higher Education; Breen, P., Ed.; IGI Global: Hershey, PA, USA, 2014.

22. Campion, G. The learning never ends: Exploring teachers' views on the transition from General English to EAP. J. Engl. Acad. Purp. 2016, 23, 59-70. [CrossRef]

23. Ding, A.; Bruce, I. The English for Academic Purposes Practitioner: Operating on Edge of Academia; Palgrave Macmillan: Basingstoke, UK, 2017.

24. Teddlie, C.; Tashakkori, A. Foundations of Mixed Methods Research: Integrating Quantitative and Qualitative Approaches in the Social and Behavioural Sciences; SAGE Publications: London, UK, 2009.

25. Creswell, J.W.; Creswell, J.D. Research Design: Qualitative, Quantitative Mixed Methods Approaches, 5th ed.; SAGE: Los Angeles, CA, USA, 2018. 
26. Bax, S. CALL-Past, present and future. System 2003, 31, 13-28. [CrossRef]

27. Ilin, G. Moodle: A way for blending VLE and face-to-face instruction in the ELT context? Turk. Online J. Educ. Technol. 2013, $12,103-112$.

28. Dashtestani, R.; Stojković, N. The use of technology in English for Specific Purposes (ESP) instruction: A literature review. J. Teach. Engl. Specif. Acad. Purp. 2015, 3, 435-456.

29. Carroll, N. E-learning-The McDonaldization of education. Eur. J. High. Educ. 2013, 3, 342-356. [CrossRef]

30. Dudeney, G.; Hockly, N. ICT in ELT: How did we get here and where are we going? ELT J. 2012, 66, 533-542. [CrossRef]

31. O'Dowd, R. Supporting in-service language educators in learning to telecollaborate. Lang. Learn. Technol. 2015, 19, 64-83.

32. Kessler, G. Formal and informal CALL preparation and teacher attitude toward Technology. Comput. Assist. Lang. Learn. 2007, 20, 173-188. [CrossRef]

33. Godwin-Jones, R. The evolving roles of language teachers: Trained coders, local researchers, global citizens. Lang. Learn. Technol. 2015, 19, 10-22.

34. Haines, K. Learning to identify and actualize affordances in a new tool. Lang. Learn. Technol. 2015, 19, 165-180.

35. Cambridge English. DELTA Syllabus Specifications. 2016. Available online: Cambridgeenglish.org (accessed on 13 July 2018).

36. BALEAP PIM. Blending Technology with EAP. 2012. Available online: https://www.baleap.org/event/moving-to-digital-learningand-teaching (accessed on 25 January 2021).

37. BALEAP. Competency Framework for Teachers of English for Academic Purposes. 2008. Available online: www.baleap.org.uk (accessed on 5 January 2019).

38. Simpson, R.; Obdalova, O. New technologies in higher education-ICT skills or digital literacy? Procedia Soc. Behav. Sci. 2014, 154, 104-111. [CrossRef] 